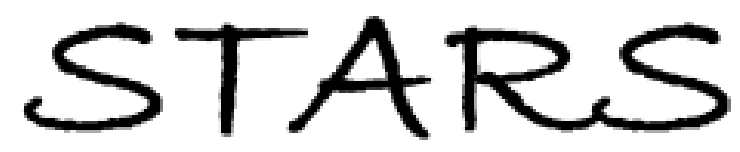

University of Central Florida

STARS

$1-1-2013$

\title{
Gamma irradiation impact on electronic carrier transport in AlGaN/GaN high electron mobility transistors
}

\author{
C. Schwarz \\ University of Central Florida
}

A. Yadav

University of Central Florida

M. Shatkhin

University of Central Florida

E. Flitsiyan

University of Central Florida

L. Chernyak

University of Central Florida

Find similar works at: https://stars.library.ucf.edu/facultybib2010

University of Central Florida Libraries http://library.ucf.edu

See next page for additional authors

This Article is brought to you for free and open access by the Faculty Bibliography at STARS. It has been accepted for inclusion in Faculty Bibliography 2010s by an authorized administrator of STARS. For more information, please contact STARS@ucf.edu.

\section{Recommended Citation}

Schwarz, C.; Yadav, A.; Shatkhin, M.; Flitsiyan, E.; Chernyak, L.; Kasiyan, V.; Liu, L.; Xi, Y. Y.; Ren, F.; Pearton, S. J.; Lo, C. F.; Johnson, J. W.; and Danilova, E., "Gamma irradiation impact on electronic carrier transport in AlGaN/GaN high electron mobility transistors" (2013). Faculty Bibliography 2010s. 4663.

https://stars.library.ucf.edu/facultybib2010/4663

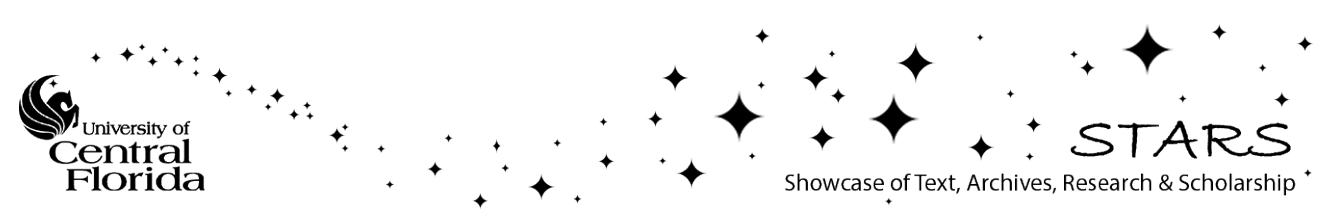




\section{Authors}

C. Schwarz, A. Yadav, M. Shatkhin, E. Flitsiyan, L. Chernyak, V. Kasiyan, L. Liu, Y. Y. Xi, F. Ren, S. J. Pearton, C. F. Lo, J. W. Johnson, and E. Danilova 


\section{Gamma irradiation impact on electronic carrier transport in AIGaN/GaN high electron mobility transistors}

Cite as: Appl. Phys. Lett. 102, 062102 (2013); https://doi.org/10.1063/1.4792240

Submitted: 20 December 2012 . Accepted: 31 January 2013 . Published Online: 11 February 2013

C. Schwarz, A. Yadav, M. Shatkhin, E. Flitsiyan, L. Chernyak, V. Kasiyan, L. Liu, Y. Y. Xi, F. Ren, S. J. Pearton,

C. F. Lo, J. W. Johnson, and E. Danilova
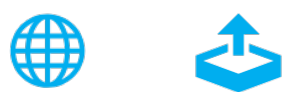

\section{ARTICLES YOU MAY BE INTERESTED IN}

Review of radiation damage in $\mathrm{GaN}$-based materials and devices

Journal of Vacuum Science \& Technology A 31, 050801 (2013); https://

doi.org/10.1116/1.4799504

Influence of 60Co $\gamma$-rays on dc performance of $\mathrm{AlGaN} / \mathrm{GaN}$ high electron mobility transistors Applied Physics Letters 80, 604 (2002); https://doi.org/10.1063/1.1445809

Electrical and optical characteristics of gamma-ray irradiated $\mathrm{AlGaN} / \mathrm{GaN}$ high electron mobility transistors

Journal of Vacuum Science \& Technology B 35, 03D107 (2017); https://

doi.org/10.1116/1.4979976

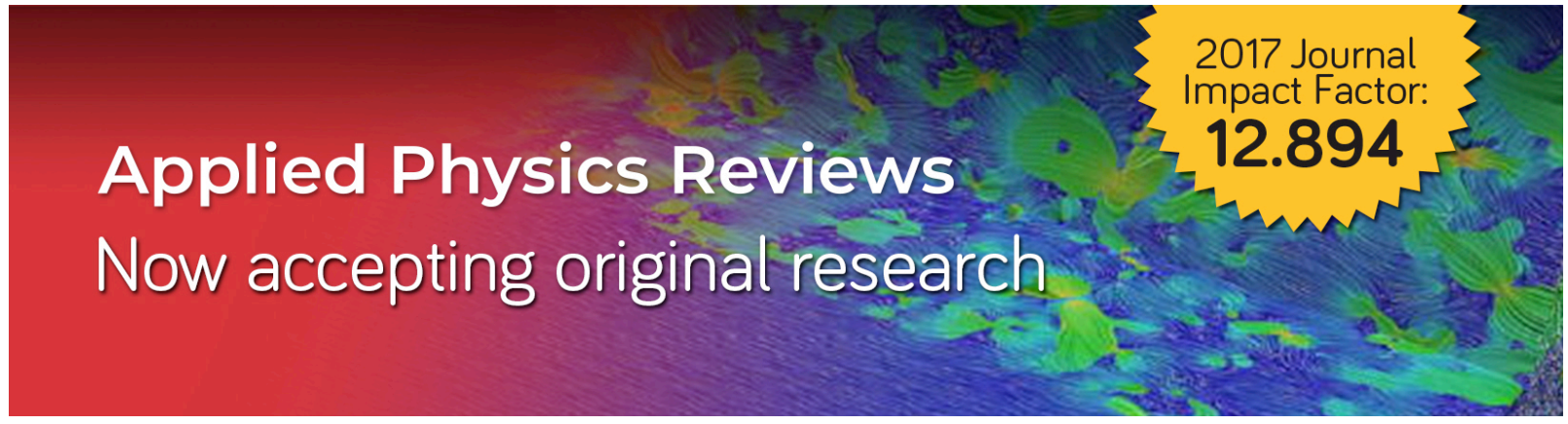




\title{
Gamma irradiation impact on electronic carrier transport in AIGaN/GaN high electron mobility transistors
}

\author{
C. Schwarz, ${ }^{1}$ A. Yadav, ${ }^{1}$ M. Shatkhin, ${ }^{1}$ E. Flitsiyan,,${ }^{1}$ L. Chernyak, ${ }^{1, a)}$ V. Kasiyan, ${ }^{2}$ L. Liu, ${ }^{3}$ \\ Y. Y. Xi, ${ }^{3}$ F. Ren, ${ }^{3}$ S. J. Pearton, ${ }^{4}$ C. F. Lo, ${ }^{5}$ J. W. Johnson, ${ }^{5}$ and E. Danilova ${ }^{6}$ \\ ${ }^{1}$ Department of Physics, University of Central Florida, Orlando, Florida 32816, USA \\ ${ }^{2}$ Department of Materials Engineering, Ben-Gurion University of the Negev, Beer-Sheva 84105, Israel \\ ${ }^{3}$ Department of Chemical Engineering, University of Florida, Gainesville, Florida 32611, USA \\ ${ }^{4}$ Department of Materials Science and Engineering, University of Florida, Gainesville, Florida 32611, USA \\ ${ }^{5}$ Kopin Corporation, Taunton, Massachusetts 02780, USA \\ ${ }^{6}$ Institute of Nuclear Physics, Tashkent 100214, Uzbekistan
}

(Received 20 December 2012; accepted 31 January 2013; published online 11 February 2013)

\begin{abstract}
AlGaN/GaN high electron mobility transistors were irradiated with ${ }^{60} \mathrm{Co}$ gamma-rays to doses up to $1000 \mathrm{~Gy}$, in order to analyze the effects of irradiation on the devices' transport properties. Temperature-dependent electron beam-induced current measurements, conducted on the devices before and after exposure to gamma-irradiation, allowed for the obtaining of activation energies related to radiation-induced defects due to nitrogen vacancies. DC current-voltage measurements were also conducted on the transistors to assess the impact of gamma-irradiation on transfer, gate, and drain characteristics. (C) 2013 American Institute of Physics. [http://dx.doi.org/10.1063/1.4792240]
\end{abstract}

III-nitride semiconductor alloys are ideal materials for the development of radiation hard electronic devices, due to the high cohesive strength of their N-Ga and N-Al bonds that create $\mathrm{GaN}, \mathrm{AlN}$, and their alloys, as well as the remarkably high thermal and mechanical stability of these compounds, ${ }^{1}$ which result in relatively high energy thresholds for displacement damage $(19-25 \mathrm{eV}) .^{2}$ Also, the wide band gap of these materials leads to a high energy threshold for the generation of electron-hole pairs induced by ionizing radiation. ${ }^{3}$ Therefore, GaN and related alloys are attractive for the development of microelectronic devices capable of reliable device operation at high temperatures and in radiation harsh environments without the need for cumbersome and expensive cooling systems and/or radiation shielding.

$\mathrm{AlGaN} / \mathrm{GaN}$ high electron mobility transistors (HEMTs) have progressed vertiginously over the past years towards greater levels of performance, resulting in foreseeable deployment in satellite, military and nuclear applications, high energy physics as well as in other industrial applications requiring high speed, high output power, and high tolerance to radiation-induced degradation. AlGaN/GaN HEMTs can operate over a very wide temperature range, when compared to their GaAs heterojunction transistor counterparts, from cryogenic temperatures, prevailing in deep space, to temperatures in excess of $700 \mathrm{~K}$, and are, thus, expected to be stable in space radiation environments.

While studies of radiation-induced defects in $\mathrm{GaN}$ based devices have attracted significant interest, only a limited amount of insight exists into the behavior of III-nitride-based heterojunction transistors after exposure to energetic ionizing radiation. Until now, most investigations of the radiation effects in $\mathrm{AlGaN} / \mathrm{GaN}$ HEMTs have employed energetic protons. ${ }^{4}$ According to these studies, proton irradiation was observed to induce a decrease in twodimensional electron gas (2DEG) sheet carrier concentration

${ }^{a)}$ E-mail: chernyak@physics.ucf.edu. and a positive threshold voltage shift with increasing proton dose. $^{4}$

In contrast to the behavior observed in proton-irradiated HEMTs, negative threshold voltage shifts and an increase in 2DEG sheet concentration have been observed in gamma $(\gamma)$-irradiated devices. ${ }^{5}$ Negative threshold voltage shifts and increase in 2DEG sheet concentration have also been observed by Polyakov et al. ${ }^{6}$ in AlGaN/GaN HEMT structures exposed to $1-\mathrm{MeV}$ neutron irradiation with doses up to $2.5 \times 10^{15} \mathrm{~cm}^{-2}$.

The objective of this work was to understand the impact of gamma irradiation on $\mathrm{AlGaN} / \mathrm{GaN}$ heterostructures fundamental properties including carrier transport and recombination. Transfer, drain, and gate characteristics were also recorded before and after irradiation. We report the effects of ${ }^{60} \mathrm{Co} \gamma$-rays doses up to $1000 \mathrm{~Gy}$ on the transport properties of $\mathrm{AlGaN} / \mathrm{GaN}$ HEMT devices through electron beam-induced current (EBIC) measurements, and then make predictions into what defects may be responsible for the radiation effects.

The HEMTs were epitaxially grown by metal-organicvapor-phase-epitaxy (MOVPE) on a sapphire substrates using a Thomas Swann Reactor. A $2 \mu \mathrm{m}$-thick carbon-doped $\mathrm{GaN}$ buffer layer was followed by a 55 -nm-thick undoped GaN channel layer, $20 \mathrm{~nm}$ of $\mathrm{Al}_{0.25} \mathrm{Ga}_{0.75} \mathrm{~N}$, and $2.5 \mathrm{~nm} \mathrm{GaN}$ cap layer.

The devices were exposed to ${ }^{60} \mathrm{Co} \gamma$-rays doses starting from $\sim 100$ Gy to a maximum total dose of $1000 \mathrm{~Gy}$. Irradiations were performed at temperatures $<50{ }^{\circ} \mathrm{C}$. During device irradiation, the samples were held in nitrogen ambient, with drain, source, and gate contacts kept electrically shorted.

Minority carrier diffusion length measurements were performed on each device between the gate and the drain in situ in Phillips XL30 scanning electron microscope (SEM) under a $20 \mathrm{kV}$ electron beam accelerating voltage using the EBIC method. Non-equilibrium carriers are generated in semiconductors when exposed to SEM electron beam. As the 
beam is moved away from the junction in a line-scan mode, the current decays, as less minority carriers are able to diffuse to the space-charge region. Minority carrier diffusion length, $L$, extracted for the line-scans, is known to be strongly influenced by the presence of defects in a material. More insight in to the EBIC technique can be found elsewhere ${ }^{7}$ (and references therein).

EBIC measurements were carried out from 25 to $125^{\circ} \mathrm{C}$ using a hot stage and an external temperature controller (Gatan). To refrain from unintentional influence of the electron beam, line scans were conducted at different locations for each temperature.

DC current-voltage (I-V) characteristics of $\mathrm{AlGaN} / \mathrm{GaN}$ HEMTs were measured predominantly at room temperature using HP 4145B Semiconductor Parameter Analyzer. The measurements were performed before and after gamma irradiation.

Fig. 1 shows the dependence of the mean value for the minority carrier diffusion length on temperature for the devices both before and after irradiation. The value of $L$ is seen to increase exponentially with temperature. This behavior is routinely seen in many semiconductors ${ }^{7}$ and can be modeled by

$$
L=L_{0}\left(-\frac{\Delta E_{a}}{2 k T}\right)
$$

Here, $L$ is the diffusion length, $L_{0}$ is a scaling factor, $k$ is the Boltzman constant, and $\Delta E_{a}$ is the thermal activation energy. The thermal activation energy, $\Delta E_{a}$, is known to represent carrier delocalization energy and as a parameter for determining the increase of the diffusion length due to the reduction in recombination. ${ }^{8}$

Temperature dependent EBIC measurements yielded a decrease in diffusion length with dose, from $0.83 \mu \mathrm{m}$ for the standard device to $0.32 \mu \mathrm{m}$ for the device exposed to the highest dose, with a corresponding increase in activation energies, $106 \mathrm{meV}$ for the standard device to $216 \mathrm{meV}$ for the device exposed to the highest dose as seen in Fig. 2. The increase of activation energy is likely an indication of the creation of deeper gamma irradiation-induced defect levels.

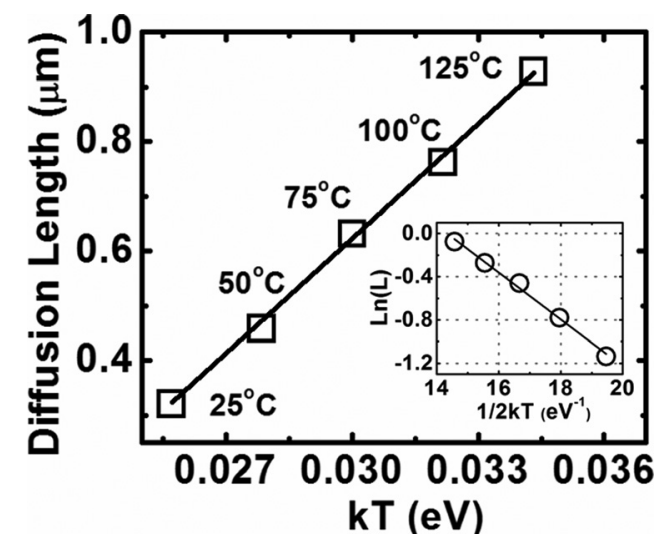

FIG. 1. Temperature dependence of $L$ for the AlGaN/GaN HEMT subjected to the highest dose of gamma-irradiation. Note: room temperature $L$ values decreased from $\sim 1 \mu \mathrm{m}$ before irradiation, to $\sim 0.35 \mu \mathrm{m}$ after irradiation. Inset: Arrhenius plot of the same data yielding the activation energy, $\Delta E_{a}$, of $216 \pm 10 \mathrm{meV} . \Delta E_{a}$ represents carrier delocalization energy, which is related to carrier recombination.

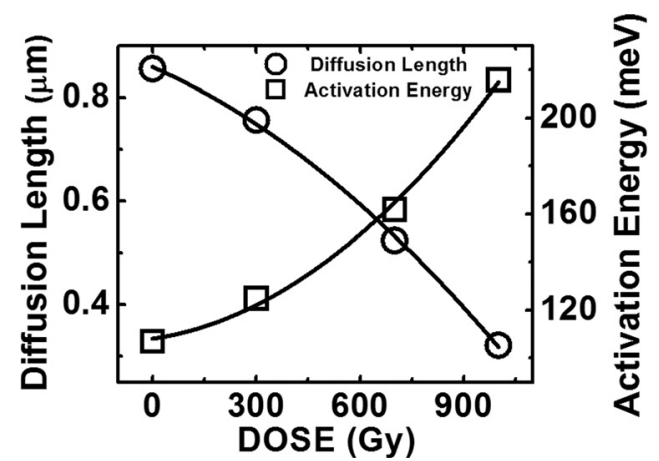

FIG. 2. Left: Experimental dependence of minority carrier diffusion length in $\mathrm{AlGaN} / \mathrm{GaN}$ HEMT on irradiation dose. The diffusion length consistently decreases as the dose of radiation increases. Right: Dependence of calculated activation energy, $\Delta E_{a}$, on irradiation dose. Note: activation energy increase indicates creation of new deeper defects with the levels in the semiconductor forbidden gap as a result of gamma irradiation.

Transfer, drain, and gate characteristics were measured before and after the irradiation with a dose of $700 \mathrm{~Gy}$. Gamma-irradiation was shown in Fig. 3 to cause a degradation of device characteristics. Fig. 3(a) specifically shows a

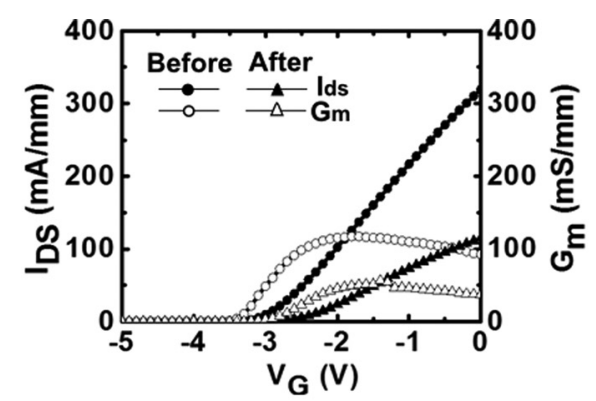

(a)

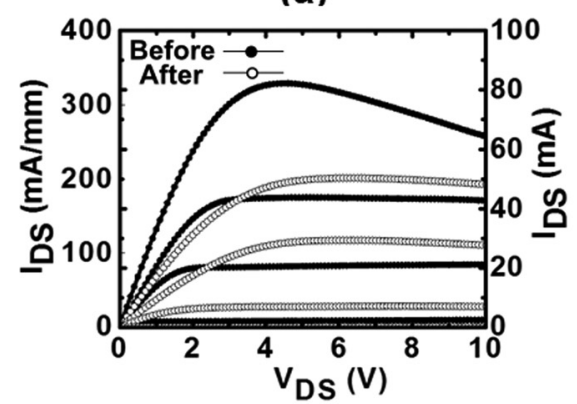

(b)

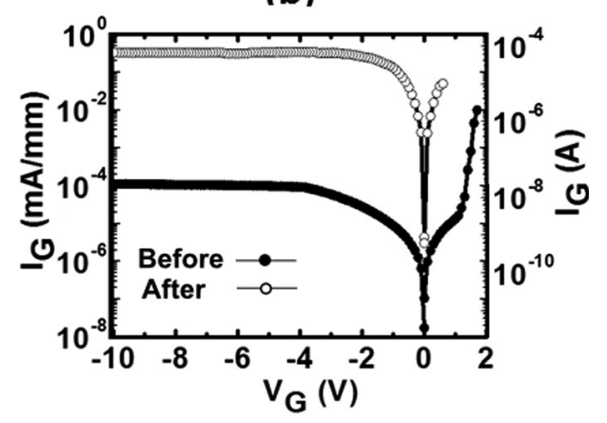

(c)

FIG. 3. DC I-V characteristics of AlGaN/GaN HEMT before and after gamma irradiation with a dose of $700 \mathrm{~Gy}$. (a) Transfer characteristics measured under $\mathrm{V}_{\mathrm{DS}}=+5 \mathrm{~V}$. (b) Drain characteristics measured under the initial $\mathrm{V}_{\mathrm{G}}=0 \mathrm{~V}$ (upper curve) with the increment of $-1 \mathrm{~V}$. (c) Gate characteristics under forward and reverse bias before and after irradiation. 
TABLE I. Impact of gamma irradiation on the figures of merit of AlGaN/GaN HEMTs. $\Delta \mathrm{I}_{\mathrm{DS}}(\%)$ was calculated from Fig. $3(\mathrm{~b})$ at $\mathrm{V}_{\mathrm{DS}}=5 \mathrm{~V}$ for the top I-V branches before and after irradiation. $\Delta \mathrm{G}_{\mathrm{m}}(\%)$ was calculated from Fig. 3(a) using the peak transconductance values before and after irradiation.

\begin{tabular}{lcccc}
\hline \hline & Reference sample & Sample A & Sample B & Sample C \\
\hline$\gamma$-Dose (Gy) & 0 & 300 & 700 & 1000 \\
Diffusion Length, $\mathrm{L}(\mu \mathrm{m})$ & $0.85 \pm 0.07$ & $0.76 \pm 0.03$ & $0.52 \pm 0.05$ & $0.32 \pm 0.03$ \\
Activation energy, $\Delta \mathrm{Ea}(\mathrm{meV})$ & $105.7 \pm 5.1$ & $125.2 \pm 3.8$ & $162.3 \pm 9.9$ & $216.1 \pm 10.0$ \\
$\Delta \mathrm{I}_{\mathrm{DS}}(\%)$ & 0 & -16.5 & -37.5 & -56.9 \\
$\Delta \mathrm{G}_{\mathrm{m}}(\%)$ & 0 & -37.9 & -54.0 & -74.1 \\
$\Delta \mathrm{V}_{\mathrm{th}}(\mathrm{V})$ & 0 & 0.1 & 0.44 & 0.67 \\
\hline \hline
\end{tabular}

reduction (after gamma-irradiation) in the drain current and transconductance as a function of device gate voltage, due to an increased trapping of carriers and dispersion of charge. A positive shift of threshold voltage, $\mathrm{V}_{\mathrm{th}}$, is also seen in Fig. 3(a). Fig. 3(b) exhibits a decrease in drain current. Fig. 3(c) illustrates the gate I-V characteristics and significant gate leakage current after irradiation, observed for both forward and reverse directions.

Since $V_{t h}=V_{b i}-q\left(N_{d}+N_{t}\right) A^{2} / 2 \varepsilon,{ }^{5}$ where $V_{b i}$ is the built-in voltage; $q$ is the charge of electron; $\mathrm{N}_{\mathrm{d}}$ is the carrier density in the 2-dimensional electron gas channel; $N_{t}$ is the trap density; A is the thickness of the 2DEG channel; and $\varepsilon$ is the dielectric constant of the AlGaN layer, one can conclude that the positive shift in the threshold voltage in Fig. 3(a) is mainly due to a decrease of the gate Schottky barrier height and the reduction of carrier concentration in the 2DEG channel, most likely because of radiation-induced damage at the metal-semiconductor interface.

Table I summarizes the relationship between dose, diffusion length decrease, activation energy increase, and changes in DC I-V characteristics. An increase in activation energy with gamma-irradiation provides insight into the creation of deep defect levels in the AlGaN/GaN devices. 0.6 MeV Compton electrons, generated by the interaction of the material with ${ }^{60} \mathrm{Co}$ gamma-photons at average energy of $1.25 \mathrm{MeV}$, are likely to create donor-type nitrogen vacancy-related defects in III-N layers. These types of defects have been reported after low-energy proton, electron, and gamma irradiation. ${ }^{9-11}$

Electron irradiation-induced nitrogen vacancy defects have been reported with activation energy values ranging from $150 \mathrm{meV}$ to $260 \mathrm{meV}$ in $\mathrm{GaN}$ after $1 \mathrm{MeV}$ electron irradiation. ${ }^{9}$ In this work, activation energies were also seen to increase from $106 \pm 5 \mathrm{meV}$, for the reference device, to $216 \pm 10 \mathrm{meV}$, for the device subjected to the highest gammairradiation dose. This increase of approximately $110 \mathrm{meV}$ is most likely related to the creation of additional deep traps due to nitrogen vacancies, induced in $\mathrm{AlGaN} / \mathrm{GaN}$ by gammairradiation. By forming deep traps, these vacancies reduce the carrier concentration, thus, increasing the recombinationrelated activation energy in the irradiated devices, which exhibit more degradation with gamma-irradiation dose. It should be noted that similar to our observations, an increase of the activation energy with dose was previously observed for proton radiation defects in III-N layers. ${ }^{9}$
Temperature dependent EBIC measurements allowed acquiring values for the activation energy as a function of gamma-irradiation dose for $\mathrm{AlGaN} / \mathrm{GaN}$ devices. I-V measurements were conducted in parallel, to assess the impact of gamma-irradiation on transfer, gate, and drain characteristics. These measurements gave insight into the correlation between gamma-irradiation dose and the creation of deeper level traps. The signature of the defects lays in the increase in activation energy values and may be a result of irradiation-induced deep nitrogen vacancy traps. Understanding the radiation effects in AlGaN/GaN devices, which various doses of gamma-photons have on carrier transport, recombination, and creation of traps, plays a significant role in determining device performance and reliability, especially for space borne applications. This information may lead to future development of devices capable of withstanding bombardment by high-energy particles.

Research at the University of Central Florida was supported in part by NSF ECCS Award No. 0900971 and NATO CLG \#984277. The work at UF was supported by an AFOSR MURI monitored by James Hwang and by HDTRA (James Reed) under contract U.S. DOD HDTRA Grant No. 1-11-1-0020.

${ }^{1}$ I. Yonenaga, Physica B 308, 1150 (2001).

${ }^{2}$ A. Ionascut-Nedelcescu, C. Carlone, A. Houdayer, H. J. von Bardeleben, J.-L. Cantin, and S. Raymond, IEEE Trans. Nucl. Sci. 49, 2733 (2002).

${ }^{3}$ C. A. Klein, J. Appl. Phys. 39, 2029 (1968).

${ }^{4}$ X. Hu, A. P. Karmarkar, B. Jun, D. M. Fleetwood, R. D. Schrimpf, R. D. Geil, R. A. Weller, B. D. White, M. Bataiev, L. J. Brillson, and U. K. Mishra, IEEE Trans. Nucl. Sci. 50, 1791 (2003).

${ }^{5}$ B. Luo, J. W. Johnson, F. Ren, K. K. Allums, C. R. Abernathy, S. J. Pearton, A. M. Dabiran, A. M. Wowchack, C. J. Polley, P. P. Chow, D. Schoenfeld, and A. G. Baca, Appl. Phys. Lett. 80, 604 (2002).

${ }^{6}$ A. Y. Polyakov, N. B. Smirnov, A. V. Govorkov, A. V. Markov, S. J. Pearton, N. G. Kolin, D. I. Merkurisov, and V. M. Boiko, J. Appl. Phys. 98, 033529 (2005).

${ }^{7}$ L. Chernyak, A. Osinsky, H. Temkin, J. W. Yang, Q. Chen, and M. A. Khan, Appl. Phys. Lett. 69, 2531 (1996).

${ }^{8}$ O. Lopatiuk, L. Chernyak, A. Osinsky, J. Q. Xie, and P. P. Chow, Appl. Phys. Lett. 87, 162103 (2005).

${ }^{9}$ M. R. Hogsed, Y. K. Yeo, M. Ahoujja, M.-Y. Ryu, J. C. Petrosky, and R. L. Hengehold, Appl. Phys. Lett. 86, 261906 (2005).

${ }^{10}$ D. C. Look, D. C. Reynolds, J. W. Hemsky, J. R. Sizelove, R. L. Jones, and R. J. Molnar, Phys. Rev. Lett. 79, 2273 (1997).

${ }^{11}$ O. Aktas, A. Kuliev, V. Kumar, R. Schwindt, S. Toshkov, D. Costescu, J. Stubbins, and I. Adesida, Solid-State Electron. 48, 471 (2004). 